\title{
Pain is a common problem in patients with ILD
}

\author{
Qinxue Shen 1,2,3, Ting Guo ${ }^{1,2,3}$, Min Song ${ }^{1,2,3}$, Wei Guo 1,2,3, Yi Zhang ${ }^{1,2,3}$, Wang Duan ${ }^{1,2,3}$, Yating Peng ${ }^{1,2,3}$, \\ Shanshan $\mathrm{Ni}^{1,2,3}$, Xiaoli Ouyang ${ }^{1,2,3}$ and Hong Peng ${ }^{1,2,3^{*}}$ (1)
}

\begin{abstract}
Background: As it is less known about the prevalence and characteristics of pain in the patients with interstitial lung disease (ILD), this paper aims at determining the characteristics of the pain in the patients with ILD.

Methods: Subjects with ILD and health controls with the matched ages and genders completed Short Form McGill Pain Questionnaire (SF-MPQ) and part of the Brief Pain Inventory (BPI) Short Form to elicit the characteristics of the pain. The patients with ILD were also assessed through Pulmonary Function Test, Six Minutes Walking Test (6MWT), modified Medical Research Council Dyspnea Scale (mMRC) for state of the illness and measured health-related quality of life (HRQoL) by Short Form-36 (SF-36) and psychological associations by Hospital Anxiety and Depression Scale (HADS).
\end{abstract}

Results: A total of 63 subjects with ILD and 63 healthy controls $(\mathrm{HC})$ were recruited in our study. The prevalence of the pain was $61.9 \%$ in ILD versus $25.3 \%$ in $\mathrm{HC}(P=0.005)$ and the median score of the pain rank index (PRI) in ILD was higher than that in $\mathrm{HC}(\mathrm{P}=0.014)$. Chest $(46.1 \%)$ accounted for the highest of overall pain locations in subjects with ILD. Associated clinical factors for pain intensity in the patients with ILD included exposure history of risk factors of ILD, with a longer distance of $6 \mathrm{MWD}(\geq 250 \mathrm{~m})$, and a higher mMRC score (2-4). The patients with ILD and pain are more likely to suffer impaired HRQoL ( $P=0.0014)$ and psychological problems $(P=0.0017, P=0.044)$.

Conclusion: The pain is common in those with ILD and the pain intensity is associated with exposure history, 6MWD, and mMRC score. The patients with ILD and pain were possibly to suffer depression, anxiety, and impaired HRQoL.

Keywords: Interstitial lung disease (ILD), Short form McGill pain questionnaire (SF-MPQ), Six minutes walking test (6MWT), Brief pain inventory (BPI), Modified medical research council dyspnea scale (mMRC), Short form-36 (SF-36), Hospital anxiety and depression scale (HADS), Healthy controls (HC)

\section{Introduction}

Interstitial lung diseases (ILDs) refer to a complex and large group of diseases that are typically characterized by the basic pathological changes of diffuse lung parenchyma, alveolar inflammation, and interstitial fibrosis with substantial morbidity and mortality $[1,2]$, which

\footnotetext{
*Correspondence: penghong66@csu.edu.cn

${ }^{1}$ Department of Respiratory and Critical Care Medicine, the Second Xiangya Hospital of Central-South University, NO.139 Renmin Middle Road, Changsha 410011, Hunan, China

Full list of author information is available at the end of the article
}

are somewhat challenging due to their unknown causes. Idiopathic interstitial pneumonia (IIP) and connective tissue disease-associated ILD (CTD-ILD) are common subtypes of ILDs. As the progress of diseases, patients with ILD are suffering from distressing dyspnea, progressive deterioration in exercise tolerance and impaired health related quality of life (HRQoL) in many patients' life domains $[3,4]$. HRQoL concerns a person's life satisfaction and happiness as affected by health, including physical, psychological and social functions [5]. As it is reported, the patients with ILD and impaired HRQoL also frequently experience pain [6-8]. original author(s) and the source, provide a link to the Creative Commons licence, and indicate if changes were made. The images or other third party material in this article are included in the article's Creative Commons licence, unless indicated otherwise in a credit line to the material. If material is not included in the article's Creative Commons licence and your intended use is not permitted by statutory regulation or exceeds the permitted use, you will need to obtain permission directly from the copyright holder. To view a copy of this licence, visit http://creativecommons.org/licenses/by/4.0/. The Creative Commons Public Domain Dedication waiver (http://creativeco mmons.org/publicdomain/zero/1.0/) applies to the data made available in this article, unless otherwise stated in a credit line to the data. 
In 2020, the current International Association for the Study of Pain (IASP) defined pain as "An unpleasant sensory and emotional experience associated with, or resembling that associated with, actual or potential tissue damages" [9]. Depressive symptoms in ILD were reported independently correlated with pain [10], and pain was also the most common symptoms in end-of-life stage of the patients with ILD $[11,12]$. However, it is less known about the prevalence, intensity, and determinants of pain in ILD, and few studies described about the pain between the patients with ILD and healthy groups.

Given the limited treatment options available to the patients with ILD, it is important to accurately identify and optimally manage coexisting conditions. A better understanding of the characteristics of pain and its influences on symptoms and physical activities will help inform approaches for prognosis of ILD. The objectives of this study were to determine the characteristics of pain (prevalence, intensity, location, and pain sensory) in patients with ILD compared with healthy, age and gender-matched control participants, the patients with ILD complicated with other respiratory disease and explore the association between pain, dyspnea, physiology function, psychological symptoms and quality of life.

\section{Materials and methods}

\section{Study overview}

This cross-sectional study used routinely collected data from the Second Xiangya hospital of central south university, a tertiary hospital in Changsha, Hunan province of China, between January of 2019 and January of 2020. This study was approved by the Medical Ethical Committee of the Second Xiangya Hospital of Central South University(Approved Number KL-2014-S009), and all participants gave written informed consent.

\section{Study population}

The ILD patients were sequentially selected from among those under hospitalization and treatments at the Second Xiangya Hospital. Inclusion criteria for the ILD group included (1) met with diagnosis criterion of ILD (the diagnosis of ILD were made by certified respiratory physicians with extensive experience with the management of ILD and according to standardized criteria [13, 14]; (2) was able to offer informed consent and medical chart; (3) was a local resident aged 40-85 years; (4) was able to complete the questionnaire interview. Exclusion criteria for the ILD group included: (1) combined with other respiratory disease; (2) with serious or unstable conditions and advanced illness, such as cardiovascular, neurological, musculoskeletal diseases and cancer, who needed to be treated as inpatients; (3) with understanding barrier; (4) was not interested in this study or rejected to sign informed consent; (5) with information missing. Healthy, age-matched control participants were recruited from Health Management Center of the Second Xiangya Hospital, included in the study if he or she (1) was a local resident aged 40-85 years; (2) without respiratory or musculoskeletal history and other advanced diseases according to the medical examination report, excluded in the study if he or she (1) was with cognitive impairment and mobility limitation; (2) was not interested in this study or rejected to sign the informed consent (Additional file 1).

\section{Procedures}

All subjects attended for 1 visit, at which time the following measures were undertaken:

Information recorded in the registry included demographic details (gender, age, BMI, diagnosis, smoking history, commodities, and use of supplemental oxygen). Pain assessment by the Short Form McGill Pain Questionnaire (SF-MPQ) and part of the Brief Pain Inventory (BPI) Short Form: SF-MPQ was used to evaluate the pain intensity of subjects, scores of different parts of SF-MPQ were calculated to characterize the pain problems [15-17]. SF-MPQ is composed of 15 representative items of MPQ, 11 of which are feelings and 4 of which are emotions. For each description, the patients were asked to rank the intensity level: 0-none, 1-mild, 2-moderate, 3-discomfort, and 4-worse. Considering that we have used SF-MPQ to measure the pain intensity, we only use BPI for the subjects to locate the pain from the body chart, which was determined by standardized body regions based on 45 anatomical areas $[18,19]$.

The subjects with ILD also completed the following measures:

Whether there was a history of exposure to risk factors related to ILD, the pulmonary function test (PFT) to investigate the lung volume compartment and pulmonary diffusing capacity, according to standard criteria [20-22]. Six minutes walking test (6MWT) was conducted without supplemental oxygen according to ATS guidelines in a 30-m corridor at the pulmonary unit within the hospital [23], heart rate and oxygen saturation, as measured by pulse oximetry $(\mathrm{SpO} 2)$ were recorded at the start and end of minutes of the test. Modified Medical Research Council Dyspnea Scale (MMRC) was used to rate their levels of dyspnea during daily life, a self-measuring tool that is associated with survival in people with IPF [24] was used to response to the changes with therapy in ILD [25]. Hospital Anxiety and Depression Scale (HADS) was used to measure the severity of anxiety and depression from 14 statements, with a higher score indicating greater anxiety or depression [26]. Short Form-36 (SF36) was used to evaluate $\mathrm{HRQ}$ oL, which was made up of 
eight dimensions, 36 projects and the sum of 8 dimension scores was SFTotal score, the higher the score was, the less damage the function it would be Ref. [27].

\section{Statistical analysis}

Continuous variables were described as mean (SD) if they were normally distributed or as median (IQR) if they were not, and categorical variables were described as counts and percentages (\%). Comparisons between groups (ILD and control; ILD with or without pain; key variables) for continuous measurements were analyzed using paired t-tests, independent t-test or Kruskal-Wallis $\mathrm{H}$ test, with categorical data analyzed using Chi Square test. The statistical analyses were conducted using SPSS (Version.25) software (Chicago, IL, USA). P $<0.05$ was considered as statistically significant.

\section{Results}

From January 2019 to December 2019, a total of 141 potential subjects with ILD and 100 healthy controls were approached (Fig. 1). A total of 63 subjects with ILD and 63 healthy control subjects were recruited, with no differences in age, gender or BMI between groups. 49 patients with ILD completed physical functions and 40 patients with ILD completed 6-min walking test. The other subjects with ILD were unable to undertake the measurement due to their poor healthy situations. All subjects and healthy controls completed all questionnaires independently.

\section{Pain problems: ILD group versus healthy control group}

The average age of all subjects was $62 \pm 9$ (Table1). The average pack years of the subjects with ILD was 16.68 years which was a much larger number to healthy controls whose average pack years was only 4.2 years $(\mathrm{P}<0.0001)$. According to SF-MPQ, the prevalence of pain was 39 (61.9\%) in ILD Group versus $16(25.3 \%)$ in HealthControl Group $(\mathrm{p}=0.005)$ and the median score of pain rank index (PRI) was 2.5 (IQR 1.0-5.0) in ILD versus 2.0 (IQR,1.0-2.0) in $\mathrm{HC}(\mathrm{P}=0.014)$. The median scores of PRI affective dimension was 2.0 (IQR 0-3.0) in ILD and 0 in HC $(\mathrm{P}<0.0001)$. But the visual an analogue scales (VAS) score and present pain intensity (PPI) rank didn't show obvious differences.

The proportion of pain location in subjects with $\mathrm{HC}$ Group and ILD Group showed significant difference in Fig. 2. In HC Group, pain locations were more evenly distributed; however, chest (46.1\%) accounted for the highest of overall pain duration in subjects with ILD, and the other locations were joint (23.1\%), limb (15.3\%), back (10.3\%), abdomen (2.6\%), and head and lumbar vertebra (2.6\%). Most subjects with pain problems experienced aching (25.6\% in ILD Group, $16.7 \%$ in HC Group), heavy (33.3\% in ILD Group, $27.8 \%$ in HC Group), shooting

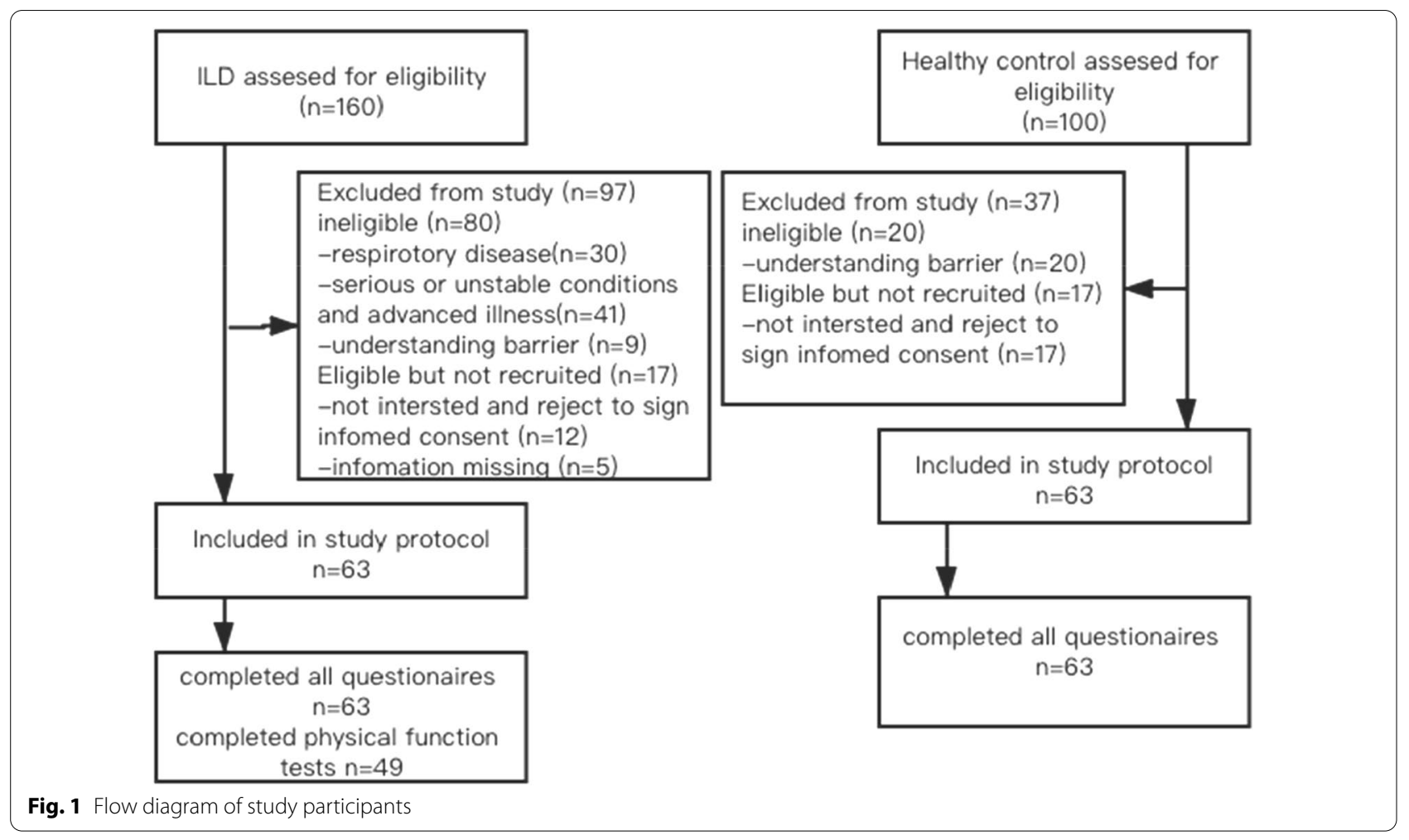


Table 1 Demographic and pain characteristics measured by SF-MPQ of participants

\begin{tabular}{|c|c|c|c|c|}
\hline Demographic & $\begin{array}{l}\text { All patients } \\
\mathrm{N}=126\end{array}$ & $\begin{array}{l}\text { ILD } \\
\mathrm{N}=63\end{array}$ & $\begin{array}{l}\text { Control } \\
N=63\end{array}$ & Pvalue \\
\hline Age (years) & $62 \pm 9$ & $61 \pm 10$ & $63 \pm 8$ & 0.730 \\
\hline$>65$ & $77(61.1 \%)$ & $40(63.5 \%)$ & $37(58.7 \%)$ & 0.714 \\
\hline Gender (Male) & $77(61.1 \%)$ & $38(60.3 \%)$ & $39(61.9 \%)$ & 0.828 \\
\hline $\mathrm{BMI}\left(\mathrm{kg} / \mathrm{m}^{2}\right)$ & $24.8 \pm 3.5$ & $25.1 \pm 3.6$ & $24.4 \pm 3.4$ & 0.327 \\
\hline Pack years (years) & $10.8 \pm 17.7$ & $16.6 \pm 21.8$ & $4.2 \pm 7.1$ & $<0.0001$ \\
\hline Pain & 55 (43.6\%) & 39 (61.9\%) & $16(25.3 \%)$ & 0.005 \\
\hline \multicolumn{5}{|l|}{ Pain intensity } \\
\hline PRI score & $2.0(1.0-4.0)$ & $2.5(1.0-5.0)$ & $2.0(1.0-2.0)$ & 0.014 \\
\hline Sensory & $2.0(1.0-2.0)$ & $2.0(2.0-3.0)$ & $2.0(1.0-2.0)$ & 0.053 \\
\hline Affective & $1.0(0-2.0)$ & $2.0(0-3.0)$ & 0 & $<0.0001$ \\
\hline VAS score & $4.0(2.7-6.0)$ & $4.5(2.8-6.0)$ & $4.0(2.3-5.8)$ & 0.163 \\
\hline \multicolumn{5}{|l|}{ PPI rank } \\
\hline No pain(n\%) & $19(34.5 \%)$ & $11(28.2 \%)$ & $8(50.0 \%)$ & 0.107 \\
\hline Mild discomfort(n\%) & $29(52.7 \%)$ & $21(53.8 \%)$ & $8(50.0 \%)$ & \\
\hline Discomfort or worse(n\%) & $7(12.7 \%)$ & $7(17.9 \%)$ & 0 & \\
\hline
\end{tabular}

For comparison, $\mathrm{X}^{2}$ test was used for binary variables, and Student's t-test or Wilcoxon nonparametric test was employed for continuous variables; the italic P-values indicate statistical significance

$B M I$ body mass index, $P R I$ pain rank index, VAS visual an analogue scales, $P P I$ present pain intensity

(33.3\% in ILD Group, 22.2\% in HC Group) in pain sensory. In HC Group, the subjects with pain also suffered hot-burning (11.1\%) and cramping (11.1\%).

\section{Clinical characteristics and symptom burden: Pain Versus No Pain in ILD Only}

In the ILD Group (Table2), 39 (61.9\%) subjects were elder than 60 years, $38(60.3 \%)$ were male, and the average BMI was $25.1 \pm 3.5 \mathrm{~kg} / \mathrm{m}^{2}$, without differences between the pain and the no-pain groups. Among the 39 (61.9\%) patients with ILD and pain, 14 (35.9\%) was diagnosed as IPF, 22 (56.4\%) was CTD-ILD and 3 (7.7\%) were other ILD (two patients with NSIP and one patient with IIP). The pain locations in 14 IPF patients distributed in chest (57.1\%), joint (21.4\%), back (14.3\%) and limb (7.1\%) and in 25 non-IPF patients distributed in chest $(40.0 \%)$, joint (24.0\%), limb (20.0\%), back (8.0\%), abdomen $(4.0 \%)$ and the other parts $(4.0 \%)$, including head and lumbar vertebra (Fig. 2). The patients with ILD and pain had more comorbidities than the patients with ILD but without pain $(P=0.040)$. More patients with ILD and pain had DLCo \% of predicted $<45 \%$ than the patients with ILD but without pain $(P=0.022)$. There was no obvious difference in FVC \% of predicted, FEV1/FVC \% and 6MWT in the patients with ILD with or without pain. When it came to dyspnea, the mMRC score of $32(82.1 \%)$ patients with ILD and pain was 2-4, higher than 13 (54.2\%) patients with ILD but without pain $(p=0.023)$. Besides, the subjects with ILD and pain showed more anxious and depression according to the HADS, in anxious dimension $23(59.0 \%)$ patients with pain and 21 (87.5\%) patients without pain were assessed for no case, 16 (41.0\%) patients with pain and $3(12.5 \%)$ patients without pain were assessed for borderline or case $(\mathrm{P}=0.017)$; in depression dimension 23 (59.0\%) with pain vs 20 (83.3\%) without pain were assessed for no case, $16(41.0 \%)$ with pain vs $4(16.7 \%)$ without pain were assessed for borderline or case $(\mathrm{P}=0.044)$. From the different dimensions of HRQL measured by RAND-36, HRQL were significantly impaired in patients with ILD and pain which can be found in SF Total score $(93.0 \pm 20.0$ in ILD with pain, $107.5 \pm 24.6$ in ILD without pain, $\mathrm{P}=0.014)$, and also performed in mental health $(p=0.029)$, bodily pain $(\mathrm{P}=0.049)$, vitality $(\mathrm{P}=0.043)$, and role emotional dimension $(\mathrm{P}=0.006)$.

\section{Pain characteristics and related factors according to SF-MPQ}

Table 3 presents pain characteristics from SF-MPQ according to key variables. There is no obvious difference of the pain intensity in the patients with ILD with age (divided line as 60 years old) and gender. Patients with a history of exposure to risk factors related to ILD had a significantly higher score in the sensory dimension $(P=0.010)$. Patients with higher mMRC score (ranging $2-4)$ showed greater pain intensity indicated by sensory dimension $(P=0.014)$, affective dimension $(P=0.037)$, and PRI $(P=0.006)$. Patients whose $6 \mathrm{MWD} \geq 250 \mathrm{~m}$ 


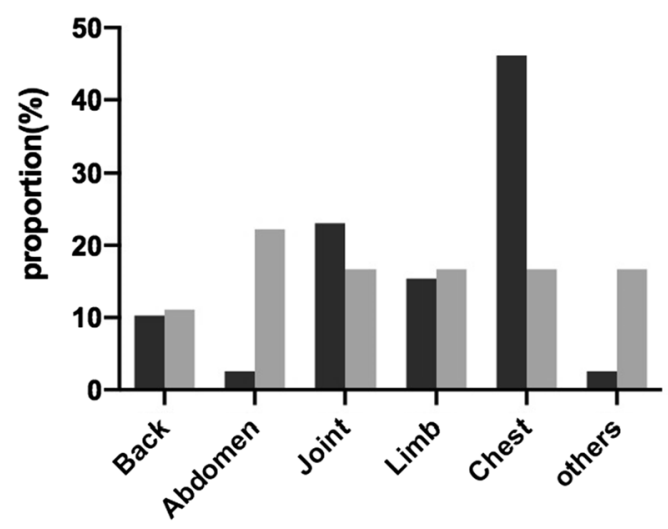

Pain location

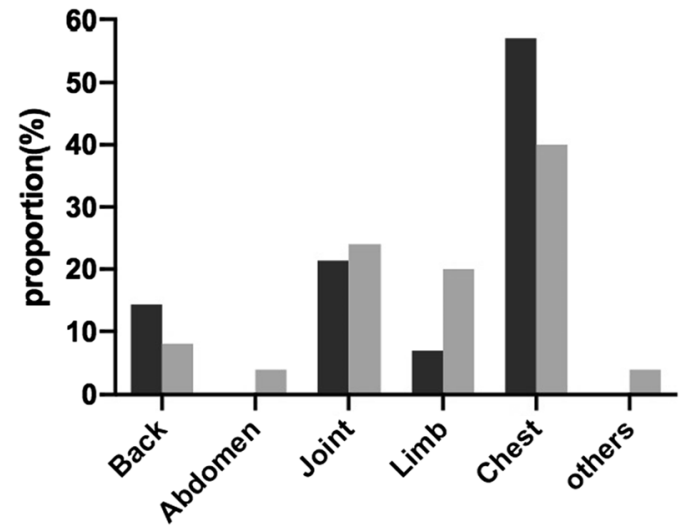

Pian location
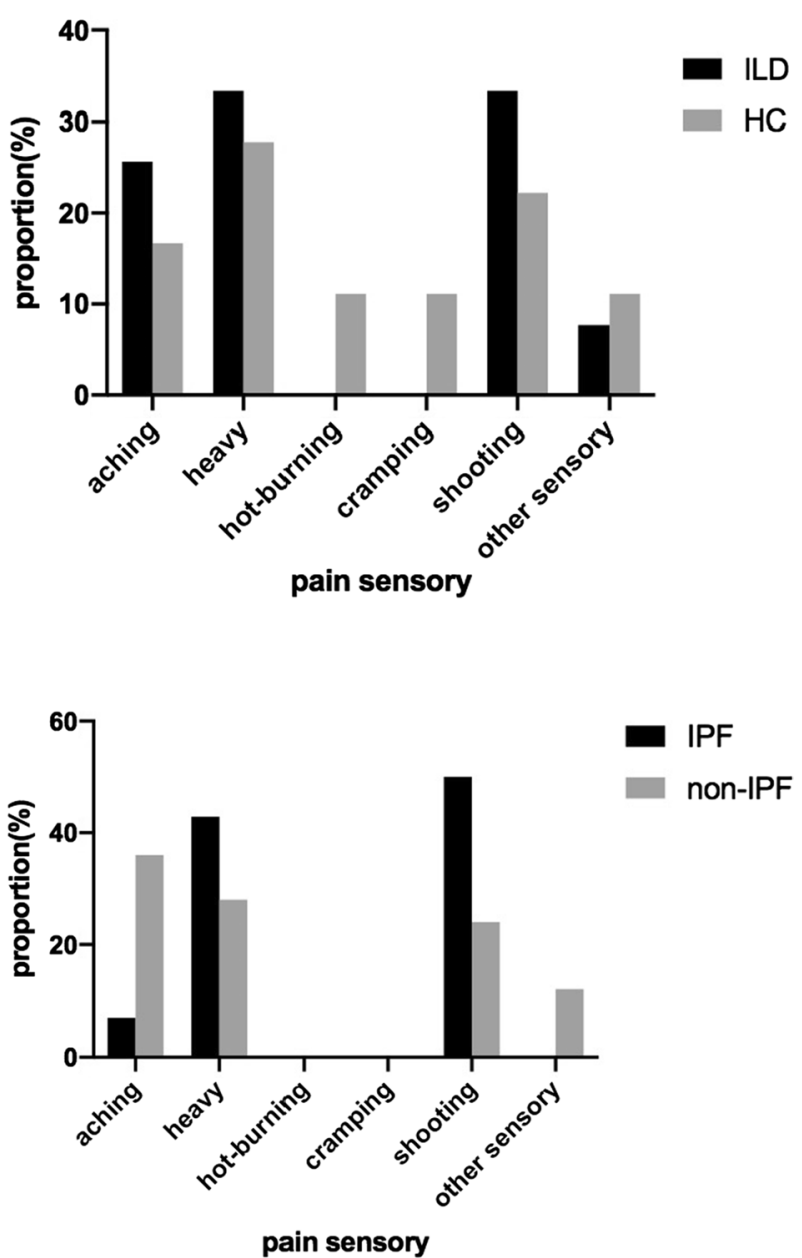

Fig. 2 Pain location and sensory in all participants. Notes: Other pain locations include head, lumbar vertebra, Other sensory include throbbing, tender, stabbing

had a significantly higher score of pain in PPI rank than the patients who had $6 \mathrm{MWD}<250 \mathrm{~m}(\mathrm{P}=0.005)$. The pain intensity of the patients with ILD showed no difference in $\mathrm{FVC} \%$ predicted, DLCO\% predicted and $\mathrm{FEV} 1 /$ FVC\%. The patients with ILD assessed by HADS on no case showed lower pain intensity than the patients assessed on borderline or case both in anxious dimension indicated by sensory dimension $(P=0.002)$, affective dimension $(\mathrm{P}=0.001)$, PRI $(\mathrm{P}=0.001)$, $\operatorname{VAS}(\mathrm{P}=0.017)$ or PPI $(\mathrm{P}=0.014)$ and in depression dimension indicated by sensory dimension $(\mathrm{P}=0.002)$, affective dimension $(\mathrm{P}=0.001)$, PRI $(\mathrm{P}<0.0001)$, VAS $(\mathrm{P}=0.013)$ or $\mathrm{PPI}$ $(\mathrm{P}=0.046)$.

\section{Discussion}

Pain problems were prevalent in the patients with ILD but only few studies were performed for this problem. It is the first time that study was performed to measure pain problems in the patients with ILD by SF-MPQ and a healthy control group, persons of similar age and gender without lung disease, were set in order to explore the characteristics of pain in the patients with ILD. In our present study, these findings indicate that pain was found commonly in both IPF and non-IPF ILDs, and the prevalence of this deficit was higher compared with the rates found in healthy controls. The main pain location in the patients with ILD was chest, joint and limb. The intensity of pain may be related to exposure history, 6MWD and $\mathrm{mMRC}$ score. Compared with the patients with ILD but without pain, patients with pain also experienced impaired physical and mental health status, which might be predominantly caused by more limitations in daily functions.

Significant pain is not considered as a typical characteristic of ILD. However, in some large cohort studies, higher prevalence of pain was found in ILD compared with that in the general population $[28,29]$. It is in line with our findings that more than half patients with ILD suffered 
Table 2 Clinical characteristics and symptom burden of ILD patients with pain and no pain

\begin{tabular}{|c|c|c|c|c|}
\hline & $\begin{array}{l}\text { All patients } \\
\mathrm{N}=63\end{array}$ & $\begin{array}{l}\text { Pain } \\
N=39\end{array}$ & $\begin{array}{l}\text { No-pain } \\
N=24\end{array}$ & Pvalue \\
\hline Age & $61 \pm 10$ & $62 \pm 10$ & $61 \pm 11$ & 0.437 \\
\hline$>60$ years & 39 (61.9\%) & $23(59.0 \%)$ & $16(66.7 \%)$ & 0.601 \\
\hline Gender (Male) & $38(60.3 \%)$ & $24(63.2 \%)$ & $14(58.3 \%)$ & 0.801 \\
\hline $\mathrm{BMI}\left(\mathrm{kg} / \mathrm{m}^{2}\right)$ & $25.1 \pm 3.5$ & $25.4 \pm 3.8$ & $24.6 \pm 2.8$ & 0.093 \\
\hline \multicolumn{5}{|l|}{ Diagnosis } \\
\hline IPF & $24(38.1 \%)$ & 14 (35.9\%) & $10(41.7 \%)$ & 0.882 \\
\hline CTD-ILD & $34(54.0 \%)$ & $22(56.4 \%)$ & $12(50.0 \%)$ & \\
\hline Others & $5(7.9 \%)$ & $3(7.7 \%)$ & $2(8.3 \%)$ & \\
\hline Smoker & $28(44.4 \%)$ & $19(48.7 \%)$ & $9(37.5 \%)$ & 0.441 \\
\hline Exposure history & $23(36.5 \%)$ & $17(43.6 \%)$ & $6(25.0 \%)$ & 0.181 \\
\hline Comorbidity & $34(53.9 \%)$ & $25(64.1 \%)$ & $9(37.5 \%)$ & 0.040 \\
\hline FVC, \% predicted & $74.5 \pm 21.8$ & $70.8 \pm 15.8$ & $80.3 \pm 28.3$ & 0.195 \\
\hline$<80$ & $32(65.3 \%)$ & $22(73.3 \%)$ & $10(52.6 \%)$ & 0.138 \\
\hline$\geq 80$ & $17(34.7 \%)$ & $8(26.7 \%)$ & $9(47.4 \%)$ & \\
\hline DLCO, \% predicted & $45.2 \pm 14.2$ & $44.1 \pm 12.8$ & $46.8 \pm 16.5$ & 0.525 \\
\hline$<45$ & 23 (48.9\%) & $18(62.1 \%)$ & $5(27.8 \%)$ & 0.022 \\
\hline$\geq 45$ & $24(51.1 \%)$ & $11(37.9 \%)$ & $13(72.2 \%)$ & \\
\hline FEV1/FVC, \% & $74.7 \pm 26.1$ & $74.4 \pm 25.3$ & $75.1 \pm 28.0$ & 0.572 \\
\hline$<70$ & $4(8.1 \%)$ & $4(10.3 \%)$ & 0 & 0.105 \\
\hline$\geq 70$ & $45(91.9)$ & 35 (89.7\%) & $10(100.0 \%)$ & \\
\hline 6MWT & $333.2 \pm 112.2$ & $329.7 \pm 100.7$ & $338.5 \pm 129.0$ & 0.801 \\
\hline $6 \mathrm{MWD}<250 \mathrm{~m}$ & $9(14.2 \%)$ & $5(55.6 \%)$ & $4(44.4 \%)$ & 0.893 \\
\hline $6 \mathrm{MWD} \geq 250 \mathrm{~m}$ & $31(49.2 \%)$ & $18(58.1 \%)$ & $13(41.9 \%)$ & \\
\hline 6MWT SpO2, before (\%) & $94.5 \pm 3.8$ & $94.7 \pm 3.4$ & $94.1 \pm 4.4$ & 0.654 \\
\hline 6MWT SpO2, later (\%) & $88.7 \pm 8.4$ & $89.9 \pm 8.5$ & $88.2 \pm 8.5$ & 0.809 \\
\hline \multicolumn{5}{|l|}{ mMRC score } \\
\hline $0-1(n \%)$ & $24(38.1 \%)$ & $7(17.9 \%)$ & $11(45.8 \%)$ & 0.023 \\
\hline $2-4(n \%)$ & 39 (61.9\%) & $32(82.1 \%)$ & $13(54.2 \%)$ & \\
\hline \multicolumn{5}{|l|}{ HAD anxious } \\
\hline No case $(n \%)$ & $43(68.2 \%)$ & $23(59.0 \%)$ & $21(87.5 \%)$ & 0.017 \\
\hline Borderline and case ( $\mathrm{n} \%)$ & $19(30.2 \%)$ & $16(41.0 \%)$ & $3(12.5 \%)$ & \\
\hline \multicolumn{5}{|l|}{ HAD depression } \\
\hline No case (\%) & $43(68.2 \%)$ & $23(59.0 \%)$ & $20(83.3 \%)$ & 0.044 \\
\hline Borderline and case (\%) & $20(31.7 \%)$ & $16(41.0 \%)$ & $4(16.7 \%)$ & \\
\hline \multicolumn{5}{|l|}{ SF-36 } \\
\hline Social functioning & $7.7 \pm 2.5$ & $7.3 \pm 2.4$ & $8.1 \pm 2.4$ & 0.265 \\
\hline Mental health & $20.1 \pm 5.8$ & $18.9 \pm 5.3$ & $33.0 \pm 6.1$ & 0.029 \\
\hline Bodily pain & $10.4 \pm 4.3$ & $9.5 \pm 4.1$ & $11.7 \pm 4.2$ & 0.049 \\
\hline Vitality & $14.4 \pm 5.6$ & $13.2 \pm 5.6$ & $16.2 \pm 5.5$ & 0.043 \\
\hline Role emotional & $3.8 \pm 1.3$ & $3.4 \pm 1.1$ & $4.3 \pm 1.3$ & 0.006 \\
\hline Physical functioning & $17.1 \pm 8.4$ & $16.2 \pm 8.1$ & $18.6 \pm 9.1$ & 0.294 \\
\hline General health & $16.3 \pm 3.6$ & $16.1 \pm 3.5$ & $16.8 \pm 3.8$ & 0.474 \\
\hline Role physical & $6.2 \pm 4.0$ & $5.7 \pm 3.7$ & $7.0 \pm 4.4$ & 0.218 \\
\hline Health Transition & $2.5 \pm 1.1$ & $2.4 \pm 1.1$ & $2.5 \pm 1.2$ & 0.661 \\
\hline SF Total score & $98.7 \pm 22.9$ & $93.0 \pm 20.0$ & $107.5 \pm 24.6$ & 0.014 \\
\hline
\end{tabular}

For comparison, $\mathrm{x}^{2}$ test was used for binary variables, and Student's t-test or Wilcoxon nonparametric test was employed for continuous variables; the italic P-values indicate statistical significance

6MWT Six minutes walking test, MMRC Modified Medical Research Council Dyspnea Scale, HADS Hospital Anxiety and Depression Scale, SF-36 Short Form-36 
Table 3 Pain characteristics from SF-MPQ according to key variables

\begin{tabular}{|c|c|c|c|c|c|c|c|}
\hline & \multicolumn{3}{|l|}{ PRI score } & \multirow{2}{*}{$\begin{array}{l}\text { VAS } \\
\text { Score }\end{array}$} & \multirow{2}{*}{$\begin{array}{l}\text { PPI rank (N\%) } \\
\text { No pain }\end{array}$} & \multirow[b]{2}{*}{ Mild discomfort } & \multirow[b]{2}{*}{$\begin{array}{l}\text { Discomfort } \\
\text { or worse }\end{array}$} \\
\hline & Sensory & Affective & Total & & & & \\
\hline \multicolumn{8}{|l|}{ Age } \\
\hline$<60$ years & $1.5(0-3.0)$ & $0(0-2.0)$ & $2.5(0-5.0)$ & $3.0(0-5.7)$ & $2(12.5)$ & $9(56.3)$ & $5(31.3)$ \\
\hline$\geq 60$ years & $1.0(0-2.0)$ & $0(0-2.0)$ & $2.0(0-4.0)$ & $3.0(0-50)$ & $3(13.0)$ & $13(56.5)$ & $7(30.4)$ \\
\hline P-value & 0.308 & 0.828 & 0.607 & 0.456 & 0.998 & & \\
\hline \multicolumn{8}{|l|}{ Gender } \\
\hline Male & $2.0(0-3.0)$ & $0(0-2.25)$ & $2.0(0-5.0)$ & $3.0(0-6.0)$ & $4(16.7)$ & $10(41.7)$ & $10(41.7)$ \\
\hline Female & $1.0(0-2.0)$ & $0(0-2.0)$ & $2.0(0-4.0)$ & $3.0(0-4.5)$ & $1(6.7)$ & $12(80.0)$ & $2(13.3)$ \\
\hline P-value & 0.344 & 0.969 & 0.541 & 0.906 & 0.063 & & \\
\hline \multicolumn{8}{|c|}{ Exposure history } \\
\hline No & $0.5(0-2.0)$ & $0(0-2.0)$ & $1.0(0-4.0)$ & $3.0(0-3.8)$ & $3(13.6)$ & $13(59.1)$ & $6(27.3)$ \\
\hline Yes & $2.0(0-3.0)$ & $1.0(0-4.0)$ & $3.0(0-6.0)$ & $5.0(0-6.0)$ & $2(11.8)$ & $9(52.9)$ & $6(35.3)$ \\
\hline P-value & 0.01 & 0.057 & 0.505 & 0.143 & 0.865 & & \\
\hline \multicolumn{8}{|l|}{ 6MWD } \\
\hline$<250 \mathrm{~m}$ & $0.5(0-2.0)$ & $0(0-2.0)$ & $1.0(0-4.0)$ & $3.0(0-3.8)$ & $2(40.0)$ & $1(20.0)$ & $2(40.0)$ \\
\hline$\geq 250 \mathrm{~m}$ & $2.0(0-3.0)$ & $1.0(0-4.0)$ & $3.0(0-6.0)$ & $5.0(0-6.0)$ & $0(11.1)$ & $15(88.9)$ & $3(16.7)$ \\
\hline$P$-value & 0.849 & 0.633 & 0.406 & 0.824 & 0.005 & & \\
\hline \multicolumn{8}{|l|}{ mMRC score } \\
\hline $0-1$ & $0(0-1.0)$ & $0(0-0.5)$ & $0(0-1.5)$ & $0(0-3.4)$ & $1(14.3)$ & $3(42.9)$ & $3(42.9)$ \\
\hline 02-Apr & $2.0(0-2.0)$ & $1.0(0-2.0)$ & $3.0(1.0-5.0)$ & $3.0(0-5.3)$ & $4(12.5)$ & $19(59.4)$ & $9(28.1)$ \\
\hline P-value & 0.014 & 0.037 & 0.006 & 0.104 & 0.706 & & \\
\hline \multicolumn{8}{|c|}{ FVC, \% predicted } \\
\hline$<80$ & $1.0(0-2.0)$ & $0(0-2.0)$ & $2.0(0-5.0)$ & $3.0(0-5.0)$ & $4(18.2)$ & $13(59.1)$ & $5(22.7)$ \\
\hline$\geq 80$ & $1.5(0-2.0)$ & $0(0-2.0)$ & $2.0(0-4.3)$ & $3.0(0-5.3)$ & $1(12.5)$ & $6(75.0)$ & $1(12.5)$ \\
\hline P-value & 0.728 & 0.908 & 0.955 & 0.605 & 0.721 & & \\
\hline \multicolumn{8}{|c|}{ DLCO, \% predicted } \\
\hline$<45$ & $2.0(0-2.5)$ & $0(0-2.5)$ & $3.0(1.0-5.0)$ & $3.0(0-5.3)$ & $2(11.1)$ & $12(66.7)$ & $4(22.2)$ \\
\hline$\geq 45$ & $1.0(0-2.0)$ & $0(0-2.0)$ & $1.0(0-4.0)$ & $3.0(0-5.0)$ & $3(27.3)$ & $6(54.5)$ & $2(18.2)$ \\
\hline P-value & 0.231 & 0.517 & 0.099 & 0.333 & 0.535 & & \\
\hline \multicolumn{8}{|l|}{ FEV1/FVC, \% } \\
\hline$<70$ & $3.0(2.0-4.0)$ & $3.0(2.0-4.0)$ & $5.0(4.0-8.0)$ & $6.0(3.0-7.0)$ & $5(19.2)$ & $17(65.4)$ & $4(15.4)$ \\
\hline$\geq 70$ & $2.5(2.0-3.0)$ & $1.5(0-3.7)$ & $4.0(3.0-5.7)$ & $6.0(3.5-7.0)$ & 0 & $2(50.0)$ & $2(50.0)$ \\
\hline P-value & 0.225 & 0.169 & 0.999 & 0.598 & 0.226 & & \\
\hline
\end{tabular}

For comparison, $x^{2}$ test was used for binary variables (*Fisher's test) and Student's t-test or Wilcoxon nonparametric test was employed for comparisons of two independent groups of continuous variables

pain in their daily life, which is much higher than that in healthy controls. When it came to the other chronic diseases, pain is also mentioned frequently but most chronic diseases show more prevalent pain problems. A metaanalysis, including 1,571 articles were identified, reporting that pain prevalence of COPD in high-quality studies ranged from 32 to $60 \%$, and comorbidity, nutritional status, QoL and several symptoms were related to pain [30]. The prevalence of pain in patients with advanced CKD had been estimated at approximately $50 \%-70 \%$ [31]. In 2018, a large healthy study in Norway [32], with 50,807 subjects, found that $43.0 \%$ in the diabetes group, and
$75.4 \%$ in the arthritis group suffered from chronic pain, and a large European survey also reported arthritis was the most common cause of pain, followed by COPD and heart disease [29]. More control groups with chronic diseases should be added in the future study to compared with the specifics of pain in ILD.

In the ILD individuals, the main pain locations were chest (46.2\%) and joint (23.1\%) among all the patients with ILD and pain. $57.1 \%$ of the patients with IPF and pain declared having chest pain, which was higher than non-IPF (40.0\%). Kaisa's study [8] also found that 31.2\% (79/253) patients with IPF experienced chest pain. But 
a British study [33] about 111 patients with fibrotic ILD found that most frequently reported painful areas of these subjects were the back (34\%) and lower limbs (25\%), and they were similar compared with the patients with and without IPF. According to literatures about pulmonary disease, the causes of chest pain remain unclear which can be related to pulmonary loss of elasticity of the parietal pleura, pathological bronchial fibrosis, thoracic vertebral deformity, costotransverse, intervertebral arthropathy and activities related to breathing and postural dysfunction [34, 35]. The incidence of joint pain in patients with CTD-ILD was higher than in the patients with IPF in our study, which was in line with the previous studies [36]. It was reported that the prevalence of joint pain in CTD-ILD patients could be explained by the high anti-cyclic citrullinated peptide antibody (anti-CCP) positivity in patients [37].

ILD Group experienced a higher pain intensity than HC Group both in feeling and emotion dimension. A higher intensity of pain in the patients with ILD was also associated with many factors in our study, including exposure history of ILD risk factors, longer distance of 6MWD $(\geq 250 \mathrm{~m}$ ), higher mMRC score (2-4) and impaired SF-36 and HAD score. When undergoing severe dyspnea, the patients normally gave extra worse results of pulmonary function test, especially FVC, \% predicted and DLCo, \% predicted, and unsatisfied 6WMT, a practical and reliable measure of exercise tolerance that was widely used to assess the functional status of the patients with IPF [38], which showed the severity of the patients' current conditions and reflect the current quality of life [39-41]. It was reported in previous studies that the association between dyspnea severity in mMRC score and intensity of pain was reported in the previous studies $[8,11]$, and the prevalence of chest pain in the patients with IPF had a positive linear relationship to increased mMRC score [8]. In our study, compared with the patients with ILD but without pain, the ILDs with pain did have a higher mMRC score. Moreover, according to the results of MPQ, the pain intensity in the patients with ILD was greatly infected by dyspnea severity. But we didn't see the relationship of pain intensity in the patients with ILD with the 6MWT SpO2 and FVC, \% predicted, and DLCO, \% predicted. Given that the patients with COPD showed obvious chronic pain and some patients with ILD also showed FEV1/FVC, \% decline under $70 \%$ in the as the disease progress, we compared the intensity of pain in the patients with ILD, who were confirmed to experience pain problems but there were only negative results. Even the severity of dyspnea may have impacts on the intensity of pain [42], no apparent paradoxical relation between pain intensity of COPD and lung function (FEV1 and FEV1 percentage predicted) had been reported in previous pain studies on COPD [30, 43-45]. This inverse relationship, was also probably caused by selection bias, also could be interpreted that other symptoms like dyspnea were more distressing than pain, leading to more focuses on dyspnea and less on pain, also causing patients to be reluctant to spontaneously report pain [46-48].

The patients with ILD and pain suffered worse quality of life and psychological deficits, like symptoms of anxiety and depression $[44,45]$. The impaired HRQoL, according to results of SF-36, except for the poor total score, was mainly performed on mental health, bodily pain, vitality, and role emotional, which was reflected in the results of SF-MPQ and HADs. We further found that the pain intensity was related to the degree of depression and anxiety. In addition to increasing dyspnea, many of the ILDs, such as sarcoidosis and connective tissue disease ILDs, are associated with extrapulmonary manifestations that may also lead to pain and add tremendous burden on HRQoL and mental health. [49, 50] Ryerson et. al. [10] reported the novel findings that baseline pain severity was associated with baseline depression score and particularly in the non-idiopathic pulmonary fibrosis population. Therefore, those indicated the need of healthcare providers, clinicians, and patients to pay greater attention to the patients with ILD and pain and consider strategies to minimize their impacts on the patients' quality of life, healthcare utilization, and prognosis.

To our knowledge, this is the first study to investigate pain in patients with ILD, including the intensity, location, type and associated factors. However, generalizability beyond this specific group and setting is limited, as only 126 subjects from one hospital were included, there are some limits in our study results to a single time-point and does not allow us to describe the changes in pain or symptoms over time. Our study may be subjected to some selection bias and as some patients at a very advanced stage of the disease or close to death were likely to be lost from the cohort. Possibilities of false negative due to small sample size and false positive due to multiple testing. Another limitation is that the score of this questionnaire may be mixed with subjective feeling, especially the VAS score, and effected by individual verbal comprehension. The last but not the least, what was the accurate cause of pain in the patient with ILD couldn't be completely sure in our study. In the future, a larger sample of cross- sectional or cohort studies may be conducted on factors related to pain intensity to further verify these results.

\section{Conclusion}

In conclusion, pain is common in the patients with ILD and the pain intensity is associated with exposure history, 6MWD, and mMRC score. The patients with ILD 
and pain have more possibility to suffer depression, anxiety and impaired HRQoL. Knowledge of pain in ILD and intervention measures should be developed for both patients and clinicians about the pain management to improve the health-related quality of life at early stages of ILD.

\section{Supplementary information}

Supplementary information accompanies this paper at https://doi. org/10.1186/s12931-020-01564-0.

Additional file 1: Table S1.Exclusion criteria of participants

\section{Abbreviations}

ILD: Interstitial lung disease; IPF: Idiopathic pulmonary fibrosis; HRQoL: Health related quality of life; SF-MPQ: McGill Pain Questionnaire; BPI: The Brief Pain Inventory short form; PFT: The pulmonary function test; 6MWT: Six minutes walking test; SpO2: Pulse oximetry; MMRC: Modified medical research council dyspnea scale; HADS: Hospital anxiety and depression scale; SF-36: Short form36; PRI: Pain rank index; VSA: Visual analogue scales; PPI: Present pain intensity.

\section{Acknowledgements}

The authors would like to acknowledge all of participants with ILD and healthy control participants who allowed us to conduct this research in an effort to improve the lives of people living with ILD.

Additional file 1: Table S1. Additional table.

\section{Authors' contributions}

SQX contributed to the design of study, the acquisition, analysis and interpretation of data, the draft and revision of the manuscript. GT contributed to the design of study, the revision of the manuscript. All authors read and approved the final manuscript. SM, GW, ZY, DW and PYT contributed to the design of study, the revision of the manuscript. NSS and OYXL contributed to the acquisition, analysis and interpretation of data, revision of the manuscript. $\mathrm{PH}$ contributed to the conception and design of study, acquisition of data, revision and final approval for the publication of the manuscript. All authors have approved the submitted version and have agreed both to be personally accountable for the author's own contributions and to ensure that questions related to the accuracy or integrity of any part of the work. All authors read and approved the final manuscript.

\section{Funding}

This work was supported by the National Natural Science Foundation of China (No. 81370164 and No. 81670062), the Natural Science Foundation of Hunan Province (No. 2015JJ4087), and the National key clinical specialist construction Programs of China, the Fundamental Research Funds for the Central Universities of Central South University (No. 2020zzts880).

\section{Availability of data and materials}

The datasets used and/or analysed during the current study are available from the corresponding author on reasonable request.

\section{Ethics approval and consent to participate}

This study was approved by the Medical Ethical Committee of the Second Xiangya Hospital of Central South University (Approved Number KL2014-S009), and all participants gave written informed consent.

\section{Consent for publication}

Not applicable.

\section{Competing interests}

The authors declare that they have no competing interests.

\section{Author details}

${ }^{1}$ Department of Respiratory and Critical Care Medicine, the Second Xiangya Hospital of Central-South University, NO.139 Renmin Middle Road,
Changsha 410011, Hunan, China. ${ }^{2}$ Research Unit of Respiratory Disease, Central-South University, Changsha, Hunan, People's Republic of China. ${ }^{3}$ The Respiratory Disease Diagnosis and Treatment Center of Hunan Province, Changsha, Hunan, People's Republic of China.

Received: 28 July 2020 Accepted: 1 November 2020

Published online: 11 November 2020

\section{References}

1. Antoniou KM, Margaritopoulos GA, Tomassetti S, Bonella F, Costabel U, Poletti V. Interstitial lung disease. Eur Respir Rev. 2014;23:40-54.

2. Mueller-Mang C, Ringl H, Herold C. Interstitial lung diseases. In: Medical Radiology. 2019. p. 261-88.

3. Baddini Martinez JA, Martinez TY, Lovetro Galhardo FP, de Castro-Pereira CA. Dyspnea scales as a measure of health-related quality of life in patients with idiopathic pulmonary fibrosis. Med Sci Monit. 2002;8:6.

4. Natalini JG, Swigris JJ, Morisset J, Elicker BM, Jones KD, Fischer A, et al. Understanding the determinants of health-related quality of life in rheumatoid arthritis-associated interstitial lung disease. Respir Med. 2017:127:1-6.

5. Belkin A, Swigris JJ. Health-related quality of life in idiopathic pulmonary fibrosis: where are we now? Curr Opin Pulm Med. 2013

6. Swigris JJ, Kuschner WG, Jacobs SS, Wilson SR, Gould MK. Health-related quality of life in patients with idiopathic pulmonary fibrosis: a systematic review. Thorax. 2005a;60(7):588-94.

7. Yount S, Beaumont J, Chen S-Y, Kaiser K, Wortman K, Brunt D, et al. Healthrelated quality of life in patients with idiopathic pulmonary fibrosis. Lung. 2016:194(2):227-34

8. Rajala K, Lehto JT, Sutinen E, Kautiainen H, Myllärniemi M, Saarto T. mMRC dyspnoea scale indicates impaired quality of life and increased pain in patients with idiopathic pulmonary fibrosis. ERJ Open Res. 2017a;3(4):00084

9. Raja SN, Carr DB, Cohen M, Finnerup NB, Flor H, Gibson S, et al. The revised International Association for the Study of Pain definition of pain: concepts, challenges, and compromises. Pain. 2020;161(9):1976-82.

10. Ryerson CJ, Arean PA, Berkeley J, Carrieri-Kohlman VL, Pantilat SZ, Landefeld CS, et al. Depression is a common and chronic comorbidity in patients with interstitial lung disease. Vol. 17, Respirology. 2012. p 525-32.

11. Ahmadi Z, Wysham NG, Lundström S, Janson C, Currow DC, Ekström M. End-of-life care in oxygen-dependent ILD compared with lung cancer: A national population-based study. Thorax. 2016;71(6):510-6.

12. Rajala K, Lehto JT, Saarinen M, Sutinen E, Saarto T, Myllärniemi M. End-oflife care of patients with idiopathic pulmonary fibrosis. BMC Palliat Care 2016;15(1):1-6.

13. Bradley B, Branley HM, Egan JJ, Greaves MS, Hansell DM, Harrison N K. Interstitial lung disease guideline: the British Thoracic Society in collaboration with the Thoracic Society of Australia and New Zealand and the Irish Thoracic Society. Thorax. 2008, v1-58.

14. Raghu G, Collard HR, Egan JJ, Martinez FJ, Behr J, Brown KK, et al. An Official ATS/ERS/JRS/ALAT Statement: Idiopathic pulmonary fibrosis: Evidence-based guidelines for diagnosis and management. Am J Respir Crit Care Med. 2011;183(6):788-824.

15. Xiao T, Zhou X, He Y, Chen Y, Qiu H, Zhang S, et al. Pain problems for patients with mild and moderate chronic obstructive pulmonary disease - a community-based study in Shanghai. J Pain Res. 2017:10:2247-52

16. Ashbrook JE, Shacklady C, Johnson S, Yeowell G, Goodwin PC. Is there an association between back pain and stress incontinence in adults with cystic fibrosis? A retrospective cross-sectional study. J Cyst Fibros. 2018;17(1):78-82

17. Schmidt RF, Willis WD, editors. SF-MPQ. In: Encyclopedia of pain. Berlin, Heidelberg: Springer Berlin Heidelberg; 2007. p. 2169.

18. Cleeland CS, Ryan KM. Pain assessment: global use of the Brief Pain Inventory. Singapore: Annals of the Academy of Medicine; 1994.

19. Keller S, Bann CM, Dodd SL, Schein J, Mendoza TR, Cleeland CS. Validity of the brief pain inventory for use in documenting the outcomes of patients with noncancer pain. Clin J Pain. 2004:20(5):309-18. 
20. Wanger J, Clausen JL, Coates A, Pedersen OF, Brusasco V, Burgos F, et al. Standardisation of the measurement of lung volumes. Eur Respir J. 2005;26(3):511-22.

21. Maclntyre N, Crapo RO, Viegi G, Johnson DC, van Grinten CPM, Brusasco $V$, et al. Standardisation of the single-breath determination of carbon monoxide uptake in the lung. Eur Respir J. 2005;26(4):720-35.

22. Miller MR, Hankinson J, Brusasco V, Burgos F, Casaburi R, Coates A, et al. Standardisation of spirometry. Eur Respir J. 2005;26:319-38.

23. Issues S, Test MW, Equipment R, Preparation P. American Thoracic Society ATS Statement : Guidelines for the Six-Minute Walk Test. Am J Respir Crit Care Med. 2002;166:111-7.

24. Rajala K, Lehto JT, Sutinen E, Kautiainen H, Myllärniemi M, Saarto T. mMRC dyspnoea scale indicates impaired quality of life and increased pain in patients with idiopathic pulmonary fibrosis. ERJ Open Res. 2017b;3(4):00084-2017.

25. Holland AE, Hill CJ, Conron M, Munro P, McDonald CF. Short term improvement in exercise capacity and symptoms following exercise training in interstitial lung disease. Thorax. 2008;63(6):549-54

26. Snaith RP. The hospital anxiety and depression scale. Health Qual Life outcomes. 2003;1:29.

27. Ware JE, Snow KK, Kosinski M, Gandek, B. SF-36 Health survey: manual and interpretation guide. Boston, MA: The Health Institute, New England Medical Center; 1993.

28. Schopflocher D, Taenzer P, Jovey R. The prevalence of chronic pain in Canada. Pain Res Manag. 2011;16(6):445-50.

29. Breivik H, Collett B, Ventafridda V, Cohen R, Gallacher D. Survey of chronic pain in Europe: prevalence, impact on daily life, and treatment. Eur J Pain. 2006;10(4):287-333.

30. van Isselt EF, Groenewegen-Sipkema KH, Eijk MS, Chavannes NH, de Waal MWM, Janssen DJA, et al. Pain in patients with COPD: A systematic review and meta-analysis. BMJ Open. 2014:4:9.

31. D. Cohen S, Davison SN, Kimmel PL. Chapter 78 - Pain and Chronic Kidney Disease. In: Kimmel PL, Rosenberg MEBT-CRD (Second E, editors. Academic Press; 2020. p. 1279-89.

32. Andenæs R, Momyr A, Brekke I. Reporting of pain by people with chronic obstructive pulmonary disease (COPD): Comparative results from the HUNT3 population-based survey. BMC Public Health. 2018;18(1):1-10.

33. Hur SA, Guler SA, Khalil N, Camp PG, Guenette JA, Ryerson CJ. Impact of psychological deficits and pain on physical activity of patients with interstitial lung disease. Lung. 2019;197(4):415-25.

34. Daut RL, Cleeland CS, Flanery RC. Development of the Wisconsin Brief Pain Questionnaire to assess pain in cancer and other diseases. Pain. 1983;17(2):197-210

35. Massery M. Musculoskeletal and neuromuscular interventions: A physical approach to cystic fibrosis. In: Journal of the Royal Society of Medicine, Supplement. 2005. p. 55-66.

36. Tzelepis GE. Toya SP. Moutsopoulos HM mimicking idiopathic interstitial pneumonias. 2008;31(1):11-20.

37. Tian M, Huang W, Ren F, Luo L, Zhou J, Huang D, et al. Comparative analysis of connective tissue disease - associated interstitial lung disease and interstitial pneumonia with autoimmune features. 2019; (Ild).

38. Du Bois RM, Weycker D, Albera C, Bradford WZ, Costabel U, Kartashov A, et al. Six-minute-walk test in idiopathic pulmonary fibrosis: Test validation and minimal clinically important difference. Am J Respir Crit Care Med. 2011;183(9):1231-7.

39. Sharp C, Adamali HI, Millar AB. A comparison of published multidimensional indices to predict outcome in idiopathic pulmonary fibrosis. ERJ Open Res. 2017:3(1):00096-2016.

40. Du Bois RM, Albera C, Bradford WZ, Costabel U, Leff JA, Noble PW et al. 6-Minute Walk Distance Is an Independent Predictor of Mortality in Patients With Idiopathic Pulmonary Fibrosis. Eur Respir J. 2014:43(5):1421-9.

41. Swigris JJ, Kuschner WG, Jacobs SS, Wilson SR, Gould MK. Health-related quality of life in patients with idiopathic pulmonary fibrosis: A systematic review. Thorax. 2005b;60(7):588-94.

42. Cheng W, Li X, Duan J, Zhou Z, Zhou A, Zhao Y, et al. Prevalence and Characteristics of Pain in Patients of Chronic Obstructive Pulmonary Disease: A Cross-Sectional Study in China Prevalence and Characteristics of Pain in Patients of Chronic Obstructive. COPD J Chronic Obstr Pulm Dis. 2020. https://doi.org/10.1080/15412555.2020.1713076.

43. Lee AL, Harrison SL, Goldstein RS, Brooks D. Pain and its clinical associations in individuals with COPD: a systematic review. Chest. 2015;147(5):1246-58

44. Janssen DJA, Wouters EFM, Parra YL, Stakenborg K, Franssen FME. Prevalence of thoracic pain in patients with chronic obstructive pulmonary disease and relationship with patient characteristics : a cross-sectiona observational study. BMC Pulm Me 2016. https://doi.org/10.1186/s1289 0-016-0210-8

45. Chen YW, Camp PG, Coxson HO, Road JD, Guenette JA, Hunt MA, et al. A Comparison of pain, fatigue, dyspnea and their impact on quality of life in pulmonary rehabilitation participants with chronic obstructive pulmonary disease. COPD J Chronic Obstr Pulm Dis. 2018;15(1):65-72.

46. van Dam, van Isselt EF, Groenewegen-Sipkema KH, van Eijk M, Chavannes $\mathrm{NH}$, Achterberg WP. Pain in patients with chronic obstructive pulmonary disease indicated for post-acute pulmonary rehabilitation. Chron Respir Dis. 2018; 2018; 16

47. Lohne V, Heer HCD, Andersen M, Miaskowski C, Kongerud J, Rustøen T. Qualitative study of pain of patients with chronic obstructive pulmonary disease. Hear Lung J Acute Crit Care. 2010;39(3):226-34.

48. Harrison SL, Lee AL, Elliott-Button HL, Shea R, Goldstein RS, Brooks D, et al. The role of pain in pulmonary rehabilitation: a qualitative study. Int J COPD. 2017;12:3289.

49. Lubin $\mathrm{M}$, Chen $\mathrm{H}$, Elicker $\mathrm{B}$, Jones KD, Collard HR, Lee JS. A comparison of health-related quality of life in idiopathic pulmonary fibrosis and chronic hypersensitivity pneumonitis. Chest. 2014;145(6):1333-8.

50. Holland AE, Fiore JF, Bell EC, Goh N, Westall G, Symons K, et al. Dyspnoea and comorbidity contribute to anxiety and depression in interstitial lung disease. Respirology. 2014;19(8):1215-21.

\section{Publisher's Note}

Springer Nature remains neutral with regard to jurisdictional claims in published maps and institutional affiliations.

\footnotetext{
Ready to submit your research? Choose BMC and benefit from:

- fast, convenient online submission

- thorough peer review by experienced researchers in your field

- rapid publication on acceptance

- support for research data, including large and complex data types

- gold Open Access which fosters wider collaboration and increased citations

- maximum visibility for your research: over 100M website views per year
}

At BMC, research is always in progress.

Learn more biomedcentral.com/submissions 